\title{
A realidade construída pela produção documental participativa
}

Leonardo Moraes Menezes

Resumo: Uma característica marcante das mídias eletrônicas na atualidade torna-se evidente pela celebração do potencial de participação da audiência, quando produtores profissionais, inclusive de suportes considerados tradicionais, desenham diferentes estratégias de engajamento do produtor amador. O conceito de participação nas narrativas audiovisuais pode ser pensado como um procedimento diferenciado de produção. Uma suposta coautoria seria um dos aspectos mais importantes na caracterização desse modo de criação e produção audiovisual. Como essa coautoria, caso exista, se configura nos discursos documentais participativos? Estas possíveis transformações na paisagem midiática nos fazem refletir sobre as facetas participativa e autoral das organizações contemporâneas da produção audiovisual.

Palavras-chave: narrativa; participação; autoria; análise do discurso

Abstract: Reality constructed through participatory documental production - A striking characteristic of today's electronic media is their potential for audience participation when producers, including those from traditional mass media, devise different audience engagement strategies. In this context, the concept of participation in audiovisual narratives can be seen as a differentiated production procedure. A presumed co-authorship would be one of the most important aspects of this mode of audiovisual creation and production. However, if such coauthorship actually exists, how does it appear in participatory documental discourses? These possible changes in the media scene lead us to reflect upon the authorial and participatory aspects of today's audiovisual organizations.

Keywords: narrative; participation; authorship; discourse analysis.

Capitaneadas pelo imediatismo intrínseco à produção de imagens na contemporaneidade, as narrativas audiovisuais de participação são, em parte, apresentadas pelos veículos de mídia como se fossem uma apreensão fiel ou próxima da realidade social. 
Atualmente, diversas correntes disputam formas distintas de se experienciar o cotidiano narrado, entre elas o romantismo - que traz uma estética externa ao mundo, geralmente encontrada na ficção - e o realismo - encarado como uma estratégia de aproximação com a realidade (JAGUARIBE, 2007). Contudo, devemos recusar essas visões como sendo absolutas, em uma perspectiva alternativa ao pós-moderno multicultural. Em sua dicotomia, elas propulsionam uma dinâmica discursiva instável ao permitir ordenamentos de mundo pelo realismo e ao mesmo tempo combater a petrificação da normatividade e do racional através do ideal romântico.

Enquanto gênero narrativo moderno que imbrica o senso de realidade, podemos dizer que o realismo é um código popularizado entre a representação e a experiência. O realismo muda conforme a época. No século XIX, por exemplo, estava ligado a um detalhamento descritivo. Já no século XX, passou a envolver a subjetividade individual (ibid.). O realismo segue com sua força na contemporaneidade porque ele se popularizou como uma pedagogia, aliado a uma ideia de rituais narrativos para as massas organizadas. Realismo é visual e narrativo. Não existe música ou arquitetura realista. Em alguma medida, ele deve dialogar com a verossimilhança.

Quando as instituições audiovisuais profissionais, detentoras de um grande público consumidor, oferecem espaço para a produção audiovisual independente da sociedade civil, em geral, caracterizam-no como uma oportunidade igualitária para todos aqueles que possuírem as condições técnicas de realizarem uma gravação de vídeo, capacidade presente atualmente em uma quantidade considerável de aparelhos celulares e máquinas fotográficas. A participação da produção amadora é parte de uma cadeia midiática que engloba desde as estratégias de consumo, o estímulo aos produtores amadores e até uma possível interação do espectador com as equipes profissional e/ou semiprofissional. Contudo, essa janela ilusória para um real sem a suposta mediação da equipe profissional das organizações midiáticas oculta critérios de seleção entre as narrativas produzidas fora da lógica industrial de produção audiovisual e enviadas por amadores e semiprofissionais. Destarte, se não promoverem diálogos frequentes com o público, permitindo em certa medida o questionamento das práticas de produção profissional, essas organizações pouco estimularão a inovação na abordagem midiática sobre a realidade.

Uma das características da cultura contemporânea de consumo se dá através da manipulação de signos na publicidade e nos produtos midiáticos, gerando a união entre mercadorias e signos, isto é, uma "mercadoria-signo" (FEATHERSTONE, 1995, p. 33). Separados dos seus objetos, os signos podem atrelar-se temporariamente a qualquer produto por múltiplas formas de associação. Pelo consumo midiático, a reprodução constante de infinitos signos e simulações aborta a separação entre o que é imagem e o que é real.

O real seria tudo o que existe e independe da minha subjetividade, da consciência. Já a realidade, uma fatia reconhecível, domesticada, analisada do real (JAGUARIBE, 2007). Ao focarmos, por exemplo, na narrativa do documentário, o público, embora não possa 
averiguar a veracidade do que lhe é relatado, é instruído pelas características do discurso não-ficcional a confiar no que lhe é dito, construindo o seu senso do real: "há muito tempo que a informação ultrapassou a barreira da verdade para evoluir no hiperespaço do nem verdadeiro nem falso, pois que aí tudo repousa sobre a credibilidade instantânea" (BAUDRILLARD, 1995, p. 95).

A análise da narrativa documental nos orienta para o pressuposto de que não existe método ou técnica específica que assegure uma captação verossímil da realidade. $\mathrm{O}$ trabalho do documentarista está na seleção e na composição de seus relatos e argumentos. Não se pode fugir à subjetividade. O documentário é uma expressão particular de cada diretor sobre determinada temática. Contudo, pensamos que a diferença do documentário está na narrativa que é tecida entre o mundo acontecido e o apresentado por quem ordena o discurso como sendo um retrato do real, principalmente quando o mesmo ordenamento se encontra distribuído em distintas mídias consumidas de forma simultânea e complementar.

Para ilustrarmos a estruturação de um discurso documental que utiliza mais de um suporte midiático, elegemos o documentário longa-metragem "A Vida em um Dia" (MACDONALD, 2011), uma produção americana da Scott Free Productions em parceria com o YouTube, site de vídeos do Google. ${ }^{1}$ A reflexão teórica se desenvolverá através do uso de categorias como atualidade, mensurando a periodicidade de exibição e a relação temporal com os acontecimentos narrados, e interatividade, o estabelecimento de uma relação de simetria entre produção e recepção, para investigarmos se a apropriação pelo público das tecnologias digitais no documentário participativo gera uma nova configuração de autoria dessas narrativas.

Amplamente conhecido por suas ações de compartilhamento de conteúdo audiovisual, mais do que por prover um serviço de vídeo on-line de qualidade, o YouTube é, ao mesmo tempo, um arcabouço comercial da cultura pop e uma vitrine para a criatividade audiovisual. ${ }^{2}$ Pertencente ao Google - uma das maiores empresas on-line na contemporaneidade -, o YouTube é um portal de vídeos com uma dinâmica distinta dos canais televisivos, pois sua organização e diversidade de conteúdos fluem em um ritmo próprio.

A cultura participativa (BURGESS e GREEN, 2009) é parte da essência empresarial do YouTube, e conteúdos gerados por usuários podem desafiar eventualmente a audiência de vídeos produzidos por profissionais de renome (GLOBO, 2013) ${ }^{3}$. Exemplos de cocriação no portal vão de serviços noticiosos, criados por usuários, a vloggings ${ }^{4}$, que podem ser apropriados e explorados pela indústria midiática profissional (BURGESS e GREEN, 2009, p. 6).

1 O referido documentário estreou no circuito brasileiro em abril de 2012 e está disponível para visualização integral e gratuita pelo próprio YouTube.

2 Exemplos que reforçam o site como um portal reconhecido por distribuir vídeos criativos estão desde ser uma das plataformas mais usadas para a viralização de vídeos e campanhas, até premiações ligadas a instituições comerciais, culturais e de cunho artístico, como o Museu Guggenheim de Nova lorque, EUA.

3 Exemplo para o ator Felipe Neto, que tem um canal no YouTube que foi o primeiro em língua portuguesa a atingir a marca de um milhão de assinantes.

4 Post de narrativas e comentários pessoais em vídeo-blogs. 
Está na cocriação o valor cultural e de mercado do site ao influenciar os modelos de negócio vigentes. As mídias amadora e profissional são distintas. Inclusive porque considerável parte dos produtores amadores não se importam de produzir vídeos sem serem pagos, motivados pela possibilidade de compartilhar suas narrativas a baixos custos.

Tais questões nos alertam para mudanças na paisagem midiática, onde as fronteiras entre mensagens midiáticas públicas e privadas se esmaecem. Nesse cenário onde as demarcações entre a produção profissional e amadora se mesclam, novos desafios são colocados, principalmente, para uma efetiva participação amadora que seja de interesse público (SHIRKY, 2011, p. 186) - que aos poucos sai do âmbito local para uma escala planetária: "Criar uma cultura participativa com benefícios maiores para a sociedade é mais difícil do que compartilhar fotos divertidas. Quanto dessa mudança social seremos capazes de compreender?" (ibid., p. 162). No entanto, vale ressaltar que a pulverização do conteúdo encontrado no YouTube oferece pouca chance para realizadores e produtos audiovisuais que não possuem redes de contatos diversificados ou que não acompanhem as estratégias discursivas dos vídeos considerados virais (SOCIAL TIMES, 2008), isto é, que atraem numerosas visualizações pela proximidade do seu conteúdo com atributos publicitários.

Possivelmente essa seja uma das razões para que diferentes pesquisas apontem para a pouca disposição dos usuários de redes sociais virtuais, como o próprio YouTube, em visualizar, comentar ou compartilhar vídeos que fujam de suas preferências de consumo, subaproveitando a capacidade de uma cultura em redes para criar novas "pontes" narrativas entre profissionais e amadores (JENKINS, 2010, p. 21). Os desafios e indagações acerca da cultura participativa do YouTube falam mais de questões culturais e políticas do que tecnológicas: quem conduz a narrativa do vídeo, quem ganha destaque, como o discurso de certos vídeos ganham autoridade como ordenamentos de visão de mundo (BURGESS e GREEN, 2009, p. 11), potencialmente influenciando o senso de realidade?

\section{Participação e construção do senso de atualidade}

Idealizado como um produto midiático de distribuição no mercado audiovisual global, o documentário "A Vida em um Dia", que retrata múltiplos acontecimentos e imagens gravados por usuários amadores e semiprofissionais durante o dia 24 de julho de 2010, iniciou como um projeto de conteúdo original do portal em parceria com uma produtora de filmes americana, ${ }^{5}$ através de um perfil dedicado no YouTube. Para estimular a participação dos usuários, o filme foi acompanhado por uma estratégia de divulgação na mídia tradicional em sinergia com ações nas redes sociais. Por esse motivo, foram analisados também os vídeos da equipe profissional, postados no perfil do filme no site YouTube, já que eles são parte integrante da estratégia de participação dos produtores amadores no projeto. Mas em que condições e em qual contexto esse projeto surgiu?

5 Scott Free Productions pertence a Ridley Scott, diretor premiado. Ele é produtor do documentário "A Vida em um Dia", dirigido por Kevin MacDonald. 
Atualmente, distintas formas de apropriação do conteúdo amador estão sendo incorporadas de maneira crescente pela mídia profissional de entretenimento, em especial, envolvendo comunidades on-line que partilhem de interesses similares (BURGESS e GREEN, 2009, p. 13; JENKINS, 2008, p. 180). Contudo, o projeto desse documentário buscou engajar os usuários pela diversidade de abordagens possíveis para se retratar o dia programado. Algumas diretrizes que supostamente aumentariam as chances de seleção dos participantes foram disponibilizadas em vídeos postados no perfil do documentário quase um mês antes da data de gravação. Outra evidência da ênfase nesse aspecto de uma narrativa heterogênea foi a escolha por um sábado para o dia das gravações, ${ }^{6}$ permitindo uma maior adesão de perfis variados de produtores amadores. O fato de também ser período de lua cheia - mostrada no início e no final do filme - pode ter contribuído para a escolha dessa data, possibilitando as gravações externas com câmeras sensíveis à baixa luminosidade nas primeiras e últimas horas/cenas do dia narrado cronologicamente.

O pacto da narrativa de qualquer documentário com o seu público é trazer, pelo olhar de uma equipe profissional e do diretor, uma abordagem que retrate, com certa verossimilhança, histórias que representem a realidade (LINS, 2004). Entretanto, permanece a necessidade de se estabelecer alguma relação com o real, gerando um amplo panorama de dúvidas. Qual foi a estratégia do diretor do "A Vida em um Dia" para criar uma narrativa que indicasse um senso de realidade a partir das gravações feitas por outros que não sob o seu direto comando profissional? A narrativa do filme foi previamente estruturada, de maneira pouco precisa, em quatro perguntas feitas pelo diretor Kevin MacDonald no primeiro vídeo postado no perfil do documentário no YouTube: O que te dá medo?; O que você ama?; O que você tem no seu bolso?; O que te faz rir?? (MACDONALD, 2011).

Todavia, compreendemos que o real não emerge no que é programável, mas "é o que fende a cena da representação, permitindo que o mundo venha perfurar o filme, arejá-lo com a irrupção do impensado e do que é irredutível ao cálculo" (CAIXETA e GUIMARÃES, 2008, p .40). "A Vida em um Dia" estabelece uma relação assimétrica com a abordagem da atualidade ao apresentar personagens geralmente estereotipados em perspectivas diferentes, por exemplo, dos telejornais, como militares americanos fazendo brincadeiras em bases estrangeiras ao invés de estarem em missões de combate. A guerra, por mais que seja um acontecimento desse dia, é retratada sem ancoramento com o factual, pois não apresenta um acontecimento que tenha valor noticioso.

Já na cena que retrata o massacre da Loveparade na Alemanha, único fato do filme que chegou às manchetes de todo o mundo, quando 21 pessoas morreram esmagadas em um túnel e mais de 500 ficaram feridas, a equipe profissional recebeu dezenas de clipes enviados sobre esse acontecimento, permitindo uma edição por múltiplas câmeras.

6 O diretor Kevin MacDonald revela em comentário nos extras do DVD que o dia 24 de julho foi escolhido por ser o primeiro sábado após a Copa do Mundo Fifa, evitando o som das vuvuzelas no fundo de áudio.

7 Na edição final do documentário, a pergunta da risada aparece como outra de igual cunho positivo: O que te faz feliz? 
Porém sem narração sobre o que estava sendo retratado. Ainda assim, a intensificação da tensão e o incômodo gerado pelas imagens ordenadas na montagem e pela trilha sonora lúgubre, acabam por criar, no espectador, o efeito catártico do choque do real (JAGUARIBE, 2007, p. 100), comum nas abordagens não-ficcionais urbanas contemporâneas. Contudo, o incidente aconteceu bem mais cedo naquele dia do que no momento próximo ao final, quando ele é mostrado no filme, sendo a narrativa estruturada a partir das primeiras horas da madrugada do dia 24, terminando próximo de meia-noite, descolando-a ainda mais do compromisso com a atualidade de valor noticioso.

A narrativa desse documentário visa estabelecer uma representação de sincronicidade ilusória, já que todos acordam ao mesmo tempo, independentemente do país ou do fuso horário, criando uma configuração temporal que subjuga o tempo dos autores amadores ao tempo da narrativa fílmica. Mas tal conformação reitera uma das mais fortes consequências e ilusões da globalização, que é a do presente simultâneo sobre o planeta, uma percepção recente de magnitude colossal e que se tornou crescente com o desenvolvimento das mídias eletrônicas, em especial a internet.

Tal dinâmica se alia à estratégica de marketing institucional do site patrocinador nesse afunilamento temporal, ao querer dar a impressão de que o projeto atua globalmente na mobilização de centenas de produtores amadores ao redor do globo em um único dia, uma vez que mais de 50\% das cenas selecionadas para o filme são estadunidenses.

Com tantas ilusões, configura-se uma crise na representação, pois também há uma crise de autoconfiança - especialmente ocidental - na capacidade humana de compreender e representar o mundo tal como ele é experienciado. Com quais conceitos fundamentamos o nosso conhecimento e a realidade em que vivemos? Gumbrecht (1998) coloca que há uma desreferencialização que impacta tanto o tempo - da contagem do tempo histórico para a lógica da simultaneidade - quanto o espaço discursivo - conforme as expressões midiáticas hegemônicas e não-hegemônicas se aproximam ou se distanciam da representação como produtora de sentidos.

Se o mundo é constituído pelo discurso - se não há mundo fora do discurso (SOARES, 2009, p. 61) -, como pensar então o problema do que é o real? O senso de atualidade se apresenta através da linguagem. Ao ser ordenado, o discurso busca instituir o real e, assim, tornar consensual a sua vontade de verdade (FOUCAULT, 2004), legitimando-se e legitimando-a. A verdade, por poder ser desfeita e refeita a qualquer momento, depende da memória e do esquecimento para tentar se fixar. Assim, ela pode reaparecer porque foram deixados rastros, pegadas em seu trajeto (SOARES, 2009, p. 66).

É necessário atentarmos que verdade e realidade são conceitos carregados de subjetividade. Por isso, a autenticação das condições de enunciação do discurso torna-se condição essencial para a validação da atualidade e do real enquanto consensos. A narrativa documental se constitui como uma relação de forças que se abrem para o conflito, quando traz ao mundo algo que não é dele, mas que nele está 
(COMOLLI, 2008, p. 74), sendo "tanto uma 'invenção da realidade' quanto um objeto do mundo" (CAIXETA e GUIMARÃES, 2008, p. 45). Se tudo faz parte de uma rede discursiva, devemos questionar de que maneira o discurso documental engendra a construção de sentidos acerca da contemporaneidade.

\section{Interatividade e refiguração da autoria}

Na indústria audiovisual, questões oriundas da estrutura organizacional das empresas midiáticas, independentemente do seu tamanho, trazem limitações adicionais para a participação discursiva plena entre produtores da sociedade civil e a mídia hegemônica (CARPENTIER, 2011, p. 147). Importante ressaltar que esse processo de interação, para a construção de discursos alternativos, pode ocorrer em diferentes níveis, dependendo se a esfera de participação ocorre através da mídia hegemônica - sendo por ela autorizada ou não -, ou em conjunto com a mídia - através de processos que geralmente demandam mais tempo e dedicação dos profissionais em compartilhar seu conhecimento e permitir que condutas e narrativas inovadoras possam ser testadas.

Considerando a interatividade como uma situação de igualdade de ação imprevisíveis pelos envolvidos (MIELNICZUK, 2001), de que maneira os usuários das plataformas interativas optam por produzir novas informações e o que faz com que elas permaneçam como base de validação para outros produtores? Pela comunicação dialógica (FLUSSER, 2007, p. 97), os sujeitos selecionam informações já existentes e disponíveis que, ao serem reestruturadas em uma nova perspectiva, podem gerar informação considerada original.

Para conservar a informação, os sujeitos procuram meios de compartilhar as informações que selecionaram, conforme suas intenções e interesses, evitando que elas desapareçam pela entropia própria da acumulação de informações, configurando, assim, a comunicação discursiva (ibid.). Apesar dessas duas maneiras de se comunicar coexistirem, o processo de promoção de diálogos efetivos entre sujeitos - isto é, a aquisição de novas informações - é dificultado pelos discursos hegemônicos que, muitas vezes, suprimem ou fazem parecer com que o diálogo seja desnecessário. Para que a comunicação possa contribuir para uma interação mais plena, é preciso que haja um certo equilíbrio entre diálogo e discurso, uma situação ainda assimétrica no campo midiático.

A interatividade entre amadores e profissionais só se efetiva quando o público pode atuar de forma a se aproximar do processo comunicativo de construção de um produto midiático - acabado ou aberto a contribuições - por meio de ferramentas e espaços físicos ou virtuais - disponibilizados pelas organizações midiáticas. O aprimoramento dos recursos tecnológicos de interatividade faz com que os usuários, acostumados a ver vídeos on-line e às ferramentas de interação disponíveis na internet, busquem, de alguma forma, "dialogar" com as narrativas antes produzidas por equipes exclusivamente profissionais em uma rede aberta e sem centro (RÜDIGER, 2002, p. 100). 
A interatividade não se dá, entretanto, de forma unilinear e homogênea. Existem diversos fatores que influenciam e limitam sua potencialidade. Ela é diferente da reatividade, quando o público apenas opta por alternativas já previstas e produzidas pela organização de mídia, como a seleção por filmes, documentários, finais alternativos para ficção e reality-shows ou a escolha de distintos caminhos narrativos em esquetes. Se tudo é predeterminado pelo produtor, consideramos o nível de interatividade sendo baixo.

De acordo com Crocomo (2007), há níveis maiores de interatividade nos meios digitais quando: primeiro, o usuário pode navegar e construir sua narrativa de modo não-linear entre os conteúdos dispostos em uma tela; no segundo nível, o usuário pode enviar mensagens para o veículo ou para outros indivíduos, mas sem resposta em tempo real, como em um fórum de discussão; no terceiro, o usuário troca diversas mensagens com retorno do veículo ou de outros membros da audiência em tempo real, como em um chat por exemplo. Essas categorizações, todavia, nos parecem incompletas para abranger as possibilidades de interação do público com as mídias eletrônicas.

Outras possibilidades de interação, como a reedição de materiais audiovisuais ,captados e disponibilizados pelo veículo ou com contribuição de imagens e áudio produzidos por amadores, geralmente são acessíveis somente na internet e com destaque temporário, tendendo a ficar cada vez mais escondidos de novos espectadores com o passar do tempo, devido ao acúmulo de novos vídeos. Além disso, quase a totalidade do material produzido profissionalmente não permite o seu uso por terceiros por conta de direitos autorais e qualquer reedição necessita de banda larga para download e upload de vídeos, o que limita a participação de grande parte dos usuários (PALACIOS, 2009, p. 259).

Nessa perspectiva, a interatividade plena, para se utilizar todos os recursos disponibilizados por sites de grande volume de acesso como o YouTube, também é limitada não só aos usuários que possuem capacidade tecnológica, mas também a competência e a motivação intelectual de manipular as ferramentas interativas como forma de expressão pessoal e coletiva (BURGESS e GREEN, 2009).

Para manter uma sensação de empoderamento do usuário mesmo após a conclusão do documentário, a equipe criou uma campanha onde o usuário poderia usar a ferramenta de edição de vídeos do próprio YouTube para acessar a timeline de edição do trailer do filme, com clipes dos vídeos e trilhas, e reeditá-la usando trechos brutos de vídeos selecionados pela equipe e a trilha sonora integral.

Contudo, por vezes o participante do projeto teve sua autonomia diminuída frente às possibilidades de complementaridade no processo de produção. Vídeos do making-of, por exemplo, revelam como a equipe demandava que os vídeos enviados não fossem previamente editados e que procurassem evidenciar as perguntas consideradas estruturais para a narrativa, proposta pelo diretor do filme, permitindo com que os profissionais tivessem um maior controle sobre o conteúdo. 
Provocar a interação através da escolha de elementos que potencializem a criação criativa talvez permita um fluxo de trocas mais autêntico, onde desencontros e questionamentos no ordenamento discursivo promoveriam uma produção documental que acolhesse o dissenso, o lugar onde a comunicação está (FLUSSER, 2008). É nessa esfera comunicacional que se estabelece um novo patamar de mediação, quando "as pessoas 'informadas' fazem um uso interativo e social da informação, alterando a sua própria conduta e agindo de maneira a transformar a realidade, individual e coletivamente" (SILVA, 2010, p. 98).

Faltam, contudo, competências técnicas, artísticas e discursivas para a produção de discursos mais críticos e inovadores, que revelem um olhar mais autoral, diverso e independente sobre representações da realidade pela produção audiovisual participativa. Focando nas plataformas digitais, pode-se dizer que mesmo com a possibilidade do usuário fazer múltiplos uploads de vídeos e da presença de ferramentas que permitam alguma interação, há uma ilusória descentralização na produção de conteúdos, enquanto a distribuição e o consumo permanecem fixados às instituições promotoras da participação. (JENKINS, 2009).

É possível, portanto, denotar que a participação nas narrativas documentais pode oxigenar a mediação das produtoras e organizações de mídia com o público, mas ainda age de forma pouco original ao retratar o real como é usualmente visto na mídia massiva. Ao enviar vídeos para a produtora, o autor amador concorda com os termos de licenciamento de conteúdo adotado pelo projeto do filme, que tem a liberdade de editá-los a seu critério, uma vez que o Google não se responsabiliza pelo conteúdo dos vídeos. Desse ponto de vista, o caráter de autoria do produtor amador é enfraquecido quando seu vídeo é adaptado para se enquadrar nas perspectivas discursivas dos profissionais de "A Vida em um Dia", sobre a realidade de um dia no mundo, cujos critérios anunciados não condizem plenamente com que é exibido na tela do cinema ou dos suportes audiovisuais eletrônicos.

A tríplice mimese de Ricoeur (1994) nos apoia para entendermos a maneira como a autoria de quem narra os vídeos, tidos como "participativos", através do discurso autorizado da mídia massiva, fica enfraquecida por uma menor autonomia do produtor amador. A relação entre autoria e autonomia se dá pela possibilidade do autor poder assumir um discurso próprio, que se diferencie ou confronte o discurso do outro, podendo potencialmente modificar ou gerar novas sociabilidades. Se, para Ricoeur, a mimese I é o mundo real acontecendo, a mimese II é o autor falando com o mundo e a mimese III é a nossa leitura sobre essa configuração, não podemos vê-las, no entanto, como isoladas, mas também não significa que elas estão diluídas. Ou seja, elas coexistem.

Concordamos que a narrativa só existe porque há uma ação, mas o seu relato sobre a realidade é apenas a constituição de uma história singular e sensata entre uma pluralidade de tramas possíveis. Nem o trabalho dos historiadores, que lidam com os fatos, gera um espelhamento: a intriga, compreendida como o dispositivo de articulação das mimeses, 
"entre um estado da experiência prática que a precede e um estágio que a sucede" (ibid., p. 87), media os acontecimentos incidentes individuais, através de sua tessitura, com a história como um todo, extraindo de uma simples sucessão de eventos uma configuração, ou seja, uma organização de incidentes numa "totalidade inteligível" (ibid., p. 103). Todo olhar para o mundo é uma construção.

A tessitura da intriga sobre a realidade nos discursos documentais participativos torna labiríntico o percurso entre as três mimeses. Ao selecionar e destacar narrativas produzidas por autores de fora da cultura profissional, mas que em sua veiculação massiva se tornam autorizadas e chanceladas como tendo caráter da realidade, gera-se, na sua leitura por uma audiência retratada como autores em potencial, uma interseção vibrantemente instável entre prefiguração, configuração e refiguração. Um embaralhamento do lugar da tríplice mimese no qual a autoria emergiria, podendo constituir uma autoria deslizante.

Mesmo nesse contexto mutável da autoria, a função do autor amador prevalece por estar conectada primordialmente à experiência do real, independentemente das circunstâncias da enunciação. Afinal, se todos os protagonismos fossem possíveis, o mundo ficaria desconfigurado. Somos o próprio acontecimento e montamos nossas histórias por códigos narrativos, advindos de um mundo codificado (FLUSSER, 2007). A experiência do real demanda por uma narratividade, pois enquanto narramos, resignificamos identidades:

(...) a construção da identidade tem a ver com discursos, objetos, práticas simbólicas que nos posicionam no mundo, dizem de nosso lugar com relação a outro (lugar) e aos outros (sujeitos); ela se constrói nessa interseção entre discursos que nos posicionam e o nosso movimento de nos posicionarmos enquanto sujeitos no mundo. (FRANÇA, 2006, p. 9)

No entanto, gerar sentido já não é mais um privilégio do autor do discurso (BARTHES, 1977). Na convergência entre quem produz e quem consome mídia, o autor não logra mais impor um limite à sua narrativa e nem controla a forma e o conteúdo de sua apresentação final. Importante dizer que nenhuma convergência é total: a participação do público não significa que ele está isolado e independente em suas capacidades interpretativas ou que possua os artifícios plenos para produzir e distribuir conteúdos que confrontem a realidade exibida pela mídia massiva.

Nesta análise da perspectiva da atualidade na mídia profissional, em sua relação com produtores amadores, percebemos estratégias que ocultam o trajeto de construção das narrativas sobre o real, como se as instituições retratadas presumissem que dar informação já basta. Mas esse é um problema para a comunicação. Na paisagem midiática contemporânea de acúmulo de informações e visões de mundo, não é limpando os ruídos oriundos do processo de estruturação do conteúdo que se faz relação, pois são os ruídos que possibilitam a criação e eventuais inovações nas narrativas midiáticas. É preciso sempre indagar-se acerca das estruturas que constituem os discursos sobre o real. Suas condições de existência e modos de dizer funcionam potencialmente como inscrições do ideológico. 
Leonardo Moraes de Menezes é doutorando em Comunicação pelo Programa de Pós-Graduação em Comunicação da Universidade Federal Fluminense (UFF), roteirista e pesquisador de mídias.

leonardomenezes@globo.com

\section{Referências}

BARTHES, Roland. Image Music Text. Londres: Fontana Press, 1977.

BAUDRILLARD, Jean. A Sociedade de Consumo. Rio de Janeiro: Elfos, 1995.

BURGESS, Jean; GREEN, Joshua. YouTube: Online Video and Participatory Culture. Cambridge: Polity Press, 2009.

CAIXETA, Ruben; GUIMARÃES, César. "Pela Distinção entre Ficção e Documentário, Provisoriamente". In: Ver e Poder, A Inocência Perdida: cinema, televisão, ficção, documentário. Belo Horizonte: Editora UFMG, 2008.

CARPENTIER, Nico. Media and Participation: a Site of Ideological-democratic Struggle. Bristol: Intellect, 2011.

COMOLLI, Jean-Louis. Ver e Poder, A Inocência Perdida: cinema, televisão, ficção, documentário. Belo Horizonte: Editora UFMG, 2008.

CROCOMO, Fernando Antonio. TV Digital e Produção Interativa: a Comunidade Manda Notícias. Florianópolis: Editora UFSC, 2007.

FEATHerstone, Mike. Cultura de Consumo e Pós-Modernismo. São Paulo: Studio Nobel, 1995.

FLUSSER, Vilém. O Mundo Codificado: Por uma Filosofia do Design e da Comunicação. São Paulo: Cosac Naify, 2007.

O Universo das Imagens Técnicas: Elogio da Superficialidade. São Paulo: Annablume, 2008.

FOUCAULT, Michel. A Ordem do Discurso. São Paulo: Edições Loyola, 2004.

FRANÇA, Vera. "Sujeito da Comunicação, Sujeitos em Comunicação". In: Na Mídia, Na Rua: Narrativas do Cotidiano. Belo Horizonte: Autêntica, 2006.

GLOBO, O. Ator e empresário, Felipe Neto quebra recordes na internet, 2013. Disponível em: $<$ http:// oglobo.globo.com/megazine/ator-empresario-felipe-neto-quebra-recordes-na-internet-7270819>. Acessado em 18 jan. 2013.

GUMBRECHT, Hans Ulrich. Modernização dos Sentidos. São Paulo: Editora 34, 1998.

JAGUARIBE, Beatriz. O Choque do Real: Estética, Mídia e Cultura. Rio de Janeiro: Rocco, 2007.

JENKINS, Henry. Cultura da convergência. São Paulo: Aleph, 2008.

. Transmedia Storytelling 101, 2009. Disponível em: <http://www.henryjenkins.org/2007/03/ transmedia_storytelling_101.html>. Acessado em 20 set. 2011.

Os Sentidos da Convergência: Entrevista com Henry Jenkins. Revista Contracampo, n. 21. Niterói: Ed UFF, 2010. 
LINS, Consuelo. O Documentário de Eduardo Coutinho: televisão, cinema e vídeo. Rio de Janeiro: Jorge Zahar Ed, 2004.

MACDONALD, Kevin. Kevin MacDonald on Life in a Day. Reino Unido, 95 minutos, 2011. Disponível em: <http://www.youtube.com/watch?v=C_4uii96xqM>. Acessado em 20 jul. 2012.

MIELNICZUK, Luciana. Considerações sobre interatividade no contexto das novas mídias. Salvador: Facom, 2001. Disponível em: <http://www.facom.ufba.br/jol/ pdf/2001_mielniczuk_ interatividadenovas>. Acessado em 11 out. 2011.

PALACIOS, Marcos. "O que é Cultura Digital?" In: SAVAZONI, Rodrigo; COHN, Sergio (orgs.). Cultura Digital.Br. Rio de Janeiro: Beco do Azougue Editorial, 2009.

RICOEUR, Paul. Tempo e Narrativa. Campinas: Papirus, 1994.

RÜDIGER, Francisco. Elementos para a Crítica da Cibercultura. São Paulo: Hacker Editores, 2002.

SHIRKY, Clay. A Cultura da Participação - Criatividade e generosidade no mundo conectado. Rio de Janeiro: Zahar, 2011.

SILVA, Luiz Martins da. "Sociedade, Esfera Pública e Agendamento". In: BENETTI, Marcia; LAGO, Claudia (orgs.). Metodologia de Pesquisa em Jornalismo. Petrópolis, Editora Vozes, 2010.

SOARES, Rosana de Lima. Margens da Comunicação: Discurso e Mídias. São Paulo: Annablume, 2009.

SOCIAL TIMES. Emerging Trends for Viral Videos and the Implications for Advertising, 2008. Disponível em: http://socialtimes.com/emerging-trends-in-viral-video-and-the-implications-foradvertising_b982. Acessado em 04 jul. 2012. 